\title{
Physicochemical Factors Governing the Partition of Pramipexole and Its Five Impurities in Microemulsion Liquid Chromatographic Systems
}

\author{
Ana M. Vemić, ${ }^{a}$ Anđelija M. Malenović, ${ }^{*},{ }^{a}$ Tijana M. Rakić, ${ }^{a}$ Nađa M. Kostić, ${ }^{a}$ \\ Biljana S. Jančić-Stojanović, ${ }^{a}$ Darko P. Ivanovića ${ }^{a}$ and Mirjana B. Medenica ${ }^{b}$
}

\author{
${ }^{a}$ Department of Drug Analysis and ${ }^{b}$ Department of Physical Chemistry and Instrumental Methods, \\ Faculty of Pharmacy, University of Belgrade, Vojvode Stepe 450, Belgrade, Serbia
}

\begin{abstract}
As microemulsões, quando usadas como fase móvel, representam uma ferramenta cromatográfica poderosa devido à sua estrutura polifásica. O objetivo deste estudo foi investigar a influência da composição da fase móvel e as propriedades das gotículas resultantes da microemulsão, bem como a lipofilicidade da fase estacionária no comportamento cromatográfico de pramipexol e suas cinco impurezas. A investigação foi realizada de acordo com o plano experimental definido pelo planejamento fatorial completo $2^{4}$ com quatro repetições do ponto central. Embora o mais afetado pelas características da coluna tenha sido o último eluente, a substância mais lipofílica, a composição e as características das gotículas de microemulsão foram igualmente importantes, de modo que o sistema de partição gotículas de microemulsão/fase estacionária provou ser o mais significativo. A lipofilicidade da fase estacionária não afetou o componente mais hidrofílico e somente o sistema de partição gotículas de microemulsão/volume do eluente causou impacto em seu comportamento. Para a separação do par crítico, foram notados efeitos quase iguais dos sistemas de partição gotículas de microemulsão/fase estacionária e volume do eluente/fase estacionária.
\end{abstract}

Microemulsions when used as mobile phases represent a very powerful chromatographic tool due to their polyphase structure. The aim of this study was to investigate the influence of the mobile phase composition and resulting microemulsion droplet's properties, as well as the stationary phase lipophilicity on the chromatographic behavior of pramipexole and its five impurities. Investigation was carried out according to the experimental plan defined by a full factorial design $2^{4}$ with four central point replications. While the most affected by column characteristics was the last eluting, most lipophilic substance, the composition and characteristics of microemulsion droplets were equally important, so the partition system microemulsion droplets/stationary phase proved to be the most significant. Stationary phase lipophilicity did not affect the most hydrophilic component and only the partition system microemulsion droplets/bulk of the eluent impacted its behavior. For the separation of the critical pair, almost equal effects of the microemulsion droplets/stationary phase and bulk of the eluent/stationary phase partition systems were noted.

Keywords: microemulsion liquid chromatography, MELC, partition behavior, experimental design, column lipophilicity, pramipexole

\section{Introduction}

\section{Microemulsions as eluents in liquid chromatography}

Intense development of chromatography in last decades caused emerging of versatile approaches in order to address different separation challenges. Microemulsions, when used as mobile phase, represent a very powerful tool due to their polyphasic structure. Comparing to the

*e-mail: andja@pharmacy.bg.ac.rs classical RP-HPLC (reversed phase-high performance liquid chromatography), the usage of microemulsion eluents provides an additional partition system between the microemulsion droplets and the bulk of the mobile phase, and thus, offers the additional capability to separate the mixture of components. For instance, in case of the oil-in-water microemulsion, the substances insoluble in water will distribute and solubilize in the hydrophobic droplet core, while the hydrophilic substances will remain in the continuous aqueous phase. This characteristic of the microemulsion eluent enables an isocratic separation 
of the compounds with prominently different polarity and represents an advantage in comparison to the other LC modes which require a gradient for the successful chromatography of such a complex mixtures. However, hydrophobic organic solvents that represent the internal phase of microemulsion eluent, as well as the molecules of surfactant, may bind to the stationary phase and therefore induce the significant changes of its characteristics. ${ }^{1}$ That is why the prediction of retention behavior may be more complicated.

As already mentioned, these advantages of the microemulsions are based on their structure and therefore, it is very important to select the proper eluent constituents in order to achieve a satisfactory separation. Microemulsions are clear, optically isotropic nano-sized dispersions of two immiscible liquids, water and oil (e.g. hydrocarbons or esters), stabilized by the addition of ionic or/and nonionic surfactant in order to achieve an organized and thermodynamically stable system. By varying the chemical composition and percentage of aqueous and oil phase, by choosing the appropriate surfactant and varying the temperature, different microemulsion systems may be formed. ${ }^{2}$ However, for the chromatographic application only oil droplets in water $(\mathrm{o} / \mathrm{w})$ and water droplets in oil (w/o) systems can be used. For the formation of stable microemulsions, the surfactants with just one carbon tail usually cannot decrease enough the surface tension between the water and oil, so the addition of the co-surfactant such as a medium chain length alcohol is required. ${ }^{3}$ The effect of the co-surfactant is presented by its ability to "pack" between the surfactant molecules around droplets, and thus, to reduce the intermolecular repulsions among them which lowers the system's surface tension to nearly zero. ${ }^{4}$ Also, the aqueous continuous phase of the microemulsion may contain additives in order to provide the optimal separation conditions. For example, buffers or acids could be added to control the $\mathrm{pH}$, and ion pair reagents or organic modifiers to alter the required separation conditions. ${ }^{4}$

\section{Definition of the investigation objective}

The aim of this study was to systematically investigate the influence of the mobile phase composition and stationary phase lipophilicity on the partition behavior on the example of pharmaceutically active substance pramipexole $((S)$-2-amino-4,5,6,7-tetrahydro-6(propylamino) benzothiazole) and its five impurities (BI-II 751 xx - impurity 1, BI-II 820 BS - impurity 2 , BI-II 546 CL - impurity 3, 2-aminobenzothiazole - impurity 4 and BI-II 786 BS - impurity 5) (Figure 1).

These substances were selected based on the fact that the impurities originate from the processes of synthesis or degradation occurred through different reaction mechanisms such as oxidation, epimerization, aromatization and dimerization. Since the resulting products have similar structures, the description of their partition behavior is particularly intriguing and offers an understanding of the new possibilities for the application of this method in pharmaceutical industry and routine quality control analysis.
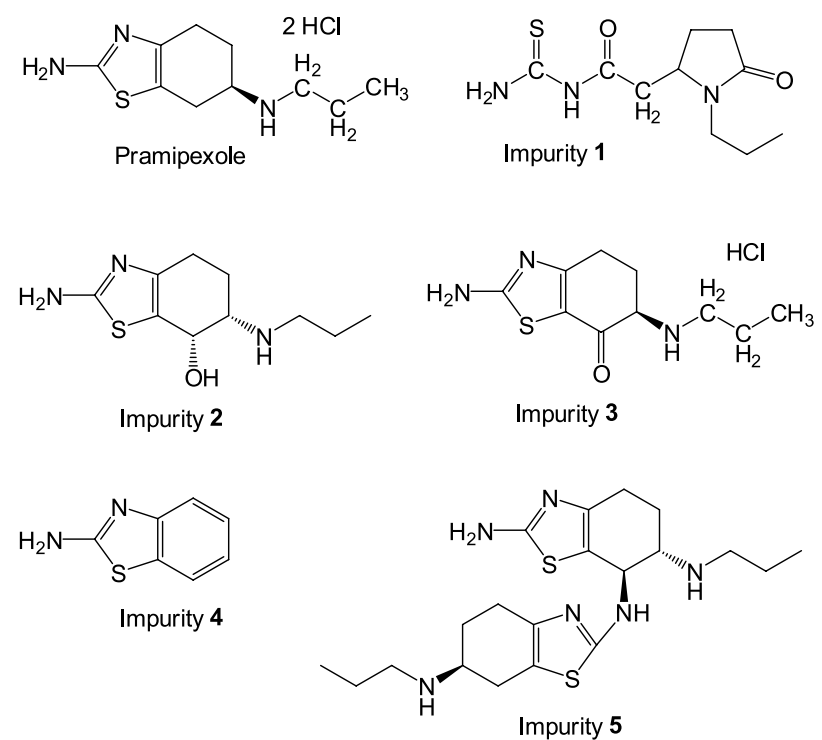

Figure 1. Chemical structures of the investigated substances: pramipexole, impurity 1 (BI-II $751 \mathrm{xx}$ ), impurity 2 (BI-II $820 \mathrm{BS}$ ), impurity 3 (BI-II 546 CL), impurity 4 (2-aminobenzothiazole), impurity 5 (BI-II 786 BS).

Some papers regarding microemulsion liquid chromatography (MELC) may be found in the literature. The evaluation of the operating parameters in order to assess its capabilities in pharmaceutical analysis was performed..$^{4-10}$ Also, the potential of MELC is proved by its expansion to the optimization of microemulsion mobile phase composition in order to model the drug penetration across blood-brain barrier. ${ }^{11}$

Apropos the selected substances, they were previously investigated by the same authors employing RP-HPLC in order to determine their pKa values, as well as for the method optimization and robustness testing. ${ }^{12-14}$ Further, for the separation of pramipexole and its enantiomer a normal-phase HPLC was used,,$^{15}$ and also, the analysis of pramipexole in biological samples was performed. ${ }^{16,17}$

However, the partition behavior of solutes in MELC system was never previously investigated in depth. As MELC provides three simultaneous partition systems - first system comprising microemulsion droplets/bulk of the eluent; second, microemulsion droplets/stationary phase and third, bulk of the eluent/stationary phase - the analytes retentions are affected by many factors and this is the first time that this kind of study is conducted. 


\section{Experimental}

\section{Chemicals}

All reagents used were of the analytical grade. Sodium dodecyl sulphate - SDS (Fluka, Sigma-Aldrich, Steinheim, Germany), Brij ${ }^{\circledR} 35$ (Sigma-Aldrich, Steinheim, Germany), butyl acetate (Sigma-Aldrich, Steinheim, Germany), n-butanol (Sigma-Aldrich, Steinheim, Germany), triethylamine - TEA (Acros Organics, Geel, Belgium), ortho-phosphoric acid (J. T. Baker, Deventer, Holland) and water (HPLC grade) obtained from Simplicity 185 (Millipore, Billerica, MA) were used to prepare the mobile phase. Working standards of pramipexole and analyzed impurities were kindly donated by Boehringer Ingelheim Pharma (Ingelheim am Rhein, Germany).

\section{Chromatographic conditions}

The chromatographic system Waters Breeze consisted of Waters 1525 Binary HPLC Pump, Waters 2487 UV-Vis detector and Breeze Software, Windows XP, for data collection were used. Separations were performed on Hypersil GOLD $\mathrm{C}_{4}, \mathrm{C}_{8}$ and $\mathrm{C}_{18} 4.6 \mathrm{~mm} \times 150 \mathrm{~mm}, 5 \mu \mathrm{m}$ particle size columns with UV detection at $262 \mathrm{~nm}$ for pramipexole, impurities $\mathbf{1 , 2 , 4}$ and $\mathbf{5}$, and at $326 \mathrm{~nm}$ for impurity $\mathbf{3}$. The flow rate was $1 \mathrm{~mL} \mathrm{~min}^{-1}$. Mobile phases were prepared according to the experimental plan defined by full factorial design $2^{4}$ with four replications in central point obtained using the Design Expert 7.0 software (Table 1). Varied factors and their levels are shown in Table 2. Mobile phases were prepared by mixing all components of the microemulsion and treating them on an ultrasonic bath for $30 \mathrm{~min}$. Eventually, the $\mathrm{pH}$ value was adjusted to 7.00 with ortho-phosphoric acid. The resulting transparent microemulsion was filtered through the $0.45 \mu \mathrm{m}$ membrane filter (Alltech, Loceren, Belgium). The samples were introduced through the Rheodyne injector valve with the $20 \mu \mathrm{L}$ sample loop.

\section{Standard solution mixture}

Stock solutions were prepared by dissolving the respective amount of the working standards in the central point mobile phase (Table 1 and Table 2) to obtain the concentrations of $1 \mathrm{mg} \mathrm{mL}^{-1}$ for pramipexole and $100 \mu \mathrm{g} \mathrm{mL}^{-1}$ for the impurities. A working standard solution mixture containing $40 \mu \mathrm{g} \mathrm{mL} \mathrm{m}^{-1}$ pramipexole and $0.2 \mu \mathrm{g} \mathrm{mL} \mathrm{m}^{-1}$ of each impurity was prepared in the central point mobile phase from the stock solutions.
Table 1. Experimental plan: full factorial design $2^{4}$ with four replications

\begin{tabular}{lcccc}
\hline Exp. & Factor $\mathrm{x}_{1}:$ & Factor $\mathrm{x}_{2}:$ & Factor $\mathrm{x}_{3}:$ & $\begin{array}{c}\text { Factor } \mathrm{x}_{4}: \\
\text { N. }\end{array}$ \\
Butyl acetate & SDS/Brijß35 & n-Butanol & TEA \\
\hline 1 & -1 & -1 & -1 & -1 \\
2 & +1 & -1 & -1 & -1 \\
3 & -1 & +1 & -1 & -1 \\
4 & +1 & +1 & -1 & -1 \\
5 & -1 & -1 & +1 & -1 \\
6 & +1 & -1 & +1 & -1 \\
7 & -1 & +1 & +1 & -1 \\
8 & +1 & +1 & +1 & -1 \\
9 & -1 & -1 & -1 & +1 \\
10 & +1 & -1 & -1 & +1 \\
11 & -1 & +1 & -1 & +1 \\
12 & +1 & +1 & -1 & +1 \\
13 & -1 & -1 & +1 & +1 \\
14 & +1 & -1 & +1 & +1 \\
15 & -1 & +1 & +1 & +1 \\
16 & +1 & +1 & +1 & +1 \\
17 & 0 & 0 & 0 & 0 \\
18 & 0 & 0 & 0 & 0 \\
19 & 0 & 0 & 0 & 0 \\
20 & 0 & 0 & 0 & 0 \\
\hline
\end{tabular}

Table 2. Analyzed factors and their levels

\begin{tabular}{lccc}
\hline \multirow{2}{*}{ Factors } & \multicolumn{3}{c}{ Factor levels } \\
\cline { 2 - 4 } & -1 & 0 & +1 \\
\hline $\mathrm{x}_{1}:$ Butyl acetate & $0.5^{\mathrm{a}}$ & 0.75 & 1.0 \\
$\mathrm{x}_{2}:$ SDS/ Brijß35 & $1.0 / 2.0$ & $1.5 / 1.5$ & $2.0 / 1.0$ \\
$\mathrm{x}_{3}: n$-Butanol & 6.0 & 7.0 & 8.0 \\
$\mathrm{x}_{4}:$ TEA & 0.5 & 0.75 & 1.0 \\
\hline
\end{tabular}

$\mathrm{a} \%(\mathrm{~m} / \mathrm{m})$ of the components.

\section{Results and Discussion}

\section{Selection of the eluent constituents}

As already mentioned in the Introduction, MELC provides three simultaneous partition systems and the analytes retentions can be affected by many factors. In such a complex system, the adequate correlation between analytes partition behavior and its appropriate interpretation could be established only if the eluent constituents are properly selected. Therefore, the preliminary experiments were performed in order to choose the suitable components for the microemulsion (internal oil phase, surfactant, co-surfactant and bulk of the mobile phase composition) and to determine the experimental domain for the experimental design. At this stage, the experiments were carried out by changing one factor at the time, i.e., one factor was changing while all the others were kept unmodified. 
Organic solvents of different polarity (butyl acetate, ethyl acetate, diisopropyl ether, $n$-hexane and $n$-octanol) were investigated as an internal organic phase for the microemulsion droplets. Even though the inner phase did not show a strong impact on the retention behavior, it seemed that butyl acetate provided slightly better separation and peaks appearance.

On the other hand, the choice of the co-surfactant appeared to be much more important. Medium chain length alcohols $n$-propanol, $n$-butanol and $n$-pentanol were tested. It was not possible to form a thermodynamically stable microemulsion using $n$-pentanol as the co-surfactant. Mobile phases containing $n$-propanol or $n$-butanol resolved analyzed substances, but $n$-butanol provided significantly shorter total run time and a better peak separation.

In the microemulsion liquid chromatography, SDS has been a widely used surfactant for the preparation of the mobile phases. However, it was found that this kind of mobile phase, containing only SDS, was not able to separate compounds with more prominent hydrophilic properties and similar chemical structure, ${ }^{10}$ which was also noted in our case. The influence of the surfactant nature on the retention times and selectivity in the separation of pramipexole and its impurities was investigated by replacing $3 \% \mathrm{~m} / \mathrm{m}$ SDS, which gave satisfactory but not the best results, with the mixtures of SDS and nonionic surfactants (Brij ${ }^{\circledR 3}$ or Tween 21) in the ratios: 1.0:2.0, 1.5:1.5 and 2.0:1.0\% (m/m). Separations performed with microemulsion eluents prepared with the mixture of SDS and Brij ${ }^{\otimes} 35$ resulted in a slight increase of the retention times of all solutes, which was profitable for the peaks eluting closely to the peak of the mobile phase (impurity $\mathbf{1}$ ) or closely to each other (impurities $\mathbf{2}$ and $\mathbf{3}$ ). In the presence of mixtures of SDS and Tween 21, within the investigated concentrations range, the microemulsion was not formed.

Since the investigated analytes were basic substances, $\mathrm{pH}$ was adjusted to 7.0 so that the analytes could remain in the molecular shape. Triethylamine (TEA) adsorbs at the solid/liquid interface and forms hydrogen bonds with the isolated silanol groups which suppress the interactions between solutes and silanol groups of the stationary phase. This effect is especially significant for basic substances, so the addition of TEA improved the symmetry of the analyzed peaks, as well as the resolution among them.

Finally, the selected microemulsion constituents (factors) and their levels are shown in Table 2.

Influence of the mobile phase composition on the partition behavior on $\mathrm{C}_{4}, \mathrm{C}_{8}$ and $\mathrm{C}_{18}$ columns

After the selection of the microemulsion components was done, a full factorial design $2^{4}$ with four replications in the central point was applied in order to define the degree of influence of the microemulsion components on the separation of pramipexole and its five impurities. A zero level (central point), in which all variables are set at their mid values was included in order to minimize the risk of missing a nonlinear relationship within the intervals. These experiments were not included in the calculation of the coefficients. ${ }^{18}$ The mathematical model that describes the full factorial design and the final factorial influences is a polynomial fourth order interaction model of the form:

$$
\begin{aligned}
y= & b_{0}+b_{1} x_{1}+b_{2} x_{2}+b_{3} x_{3}+b_{4} x_{4}+b_{12} x_{1} x_{2}+b_{13} x_{1} x_{3}+ \\
& b_{14} x_{1} x_{4}+b_{23} x_{2} x_{3}+b_{24} x_{2} x_{4}+b_{34} x_{3} x_{4}+b_{123} x_{1} x_{2} x_{3}+ \\
& b_{134} x_{1} x_{3} x_{4}+b_{234} x_{2} x_{3} x_{4}+b_{1234} x_{1} x_{2} x_{3} x_{4}
\end{aligned}
$$

where $y$ represents the estimated response, $b_{0}$ is the average experimental response, the coefficients $b_{1}-b_{4}$ are the estimated effects of the considered factors, while the extent to which these terms affect the method performance is called the main effect. The coefficients $b_{12}-b_{34}, b_{123}-b_{234}$ and $b_{1234}$ are the interaction terms of two, three and four factors, respectively.

Since the goal of this investigation was to estimate the mutual influence of the column lipophilicity and microemulsion eluent, the same sets of experiments were carried out on all three investigated columns.

As the system output, retention factor $\mathrm{k}$ was chosen due to its ability to appropriately describe the component retention on the column, ${ }^{19}$ and it is equal to the distance between $\mathrm{t}_{0}$ and the band center, divided by the distance from injection to $t_{0}$.

$\mathrm{k}=\left(\mathrm{t}_{\mathrm{R}}-\mathrm{t}_{0}\right) / \mathrm{t}_{0}$

The results obtained from the experiments performed on all three columns are shown in Table 3 .

The next step was the calculation of the factors' effects employing Design Expert 7.0 software. The values of the coefficients (equation 1) are shown in Table 4. In order to simplify the review of the effects, only single factors and two factor interaction terms are presented. Positive values of the coefficients signify that the increase of the observed factor leads to the increase of the response, while negative coefficient means that the response will decrease with the higher factor level.

The significance of factors' effects was estimated according to $p$-value. For $p$-values less than 0.05 model terms are significant. Factors with the most prominent influence on the observed responses are given in Table 5.

Analyzing the given Table 5, it could be noticed that the most influential factor appears to be factor $\mathrm{x}_{3}$, the concentration of the co-surfactant (n-butanol); due to its 
Table 3. Obtained responses for the retention factors of pramipexole $(\mathrm{P})$ and the impurities (1-5)

\begin{tabular}{|c|c|c|c|c|c|c|c|c|c|c|c|c|c|c|c|c|c|c|}
\hline \multirow{2}{*}{ Exp. N. } & \multicolumn{6}{|c|}{$\mathrm{C} 4$} & \multicolumn{6}{|c|}{$\mathrm{C} 8$} & \multicolumn{6}{|c|}{$\mathrm{C} 18$} \\
\hline & $\mathrm{k}_{1}$ & $\mathrm{k}_{2}$ & $\mathrm{k}_{3}$ & $k_{p}$ & $\mathrm{k}_{4}$ & $\mathrm{k}_{5}$ & $\mathrm{k}_{1}$ & $\mathrm{k}_{2}$ & $\mathrm{k}_{3}$ & $k_{\mathrm{P}}$ & $\mathrm{k}_{4}$ & $\mathrm{k}_{5}$ & $\mathrm{k}_{1}$ & $\mathrm{k}_{2}$ & $\mathrm{k}_{3}$ & $k_{p}$ & $\mathrm{k}_{4}$ & $\mathrm{k}_{5}$ \\
\hline 1 & 0.513 & 1.375 & 1.571 & 1.875 & 2.238 & .175 & .501 & 1.562 & 1.744 & .143 & 2.286 & 9.412 & 0.520 & 1.693 & 1.903 & 2.389 & 2.389 & 11.429 \\
\hline & 0.501 & 1.099 & 1.301 & 1.503 & 1.980 & 5.016 & 522 & 1.359 & 1.567 & 859 & 2.167 & 7.265 & 0.561 & 1.434 & 1.406 & 1.994 & 2.287 & 7.958 \\
\hline & 0.307 & 1.050 & 1.166 & 1.383 & 1.588 & 4.333 & 292 & 1.264 & 1.369 & 1.688 & 1.708 & 5.932 & 0.489 & 1.672 & 1.770 & 2.193 & 2.193 & 7.749 \\
\hline & 0.505 & 1.273 & 1.405 & 1.611 & 1.868 & 4.553 & 0.476 & 1.483 & 1.589 & 1.900 & 1.976 & 6.051 & 0.525 & 1.556 & 1.687 & 2.030 & 2.030 & 6.627 \\
\hline & 0.419 & 0.812 & 0.935 & 1.070 & 1.454 & 2.932 & 0.442 & 1.057 & 1.183 & 1.418 & 1.673 & 4.788 & 0.472 & 1.017 & 1.164 & 1.408 & 1.684 & 4.541 \\
\hline & 479 & 0.790 & 0.925 & 1.036 & 1.478 & 2.490 & 0.575 & 1.014 & 1.153 & 1.331 & 1.677 & 3.498 & 0.482 & 0.963 & 1.111 & 1.323 & 1.602 & 3.901 \\
\hline & 0 & 0.928 & 0.995 & 1.104 & 1.385 & 2.6 & & & 1.213 & 1.418 & 1.539 & & & 1.269 & 1.052 & 1.590 & 1.590 & 74 \\
\hline & 0.414 & 0.801 & 0.874 & 0.955 & 1.251 & 2.164 & 0.415 & 0.936 & 0.998 & 1.135 & 1.319 & 2.888 & 0.467 & 1.078 & 1.140 & 1.327 & 1.327 & 3.570 \\
\hline & 0.622 & 1.129 & 1.341 & 1.569 & 2.404 & 5.315 & 0.619 & 1.309 & 1.529 & 1.865 & 2.652 & 7.367 & 0.637 & 1.469 & 1.706 & 2.152 & 2.866 & 9.392 \\
\hline 10 & 0.390 & 1.051 & 1.237 & 1.430 & 2.232 & 4.516 & 82 & 0.930 & 0.957 & 1.405 & 2.092 & 2. & 0.648 & 1.321 & 1.544 & 1.879 & 2.582 & 7.124 \\
\hline 11 & & 1.115 & 1.260 & 1.482 & & & & & 1.393 & & 2.114 & & & & 1.507 & 1.912 & 2.218 & 6.556 \\
\hline 12 & 0.365 & 0.870 & 0.979 & 1.151 & 1.577 & 3.26 & 0.355 & 1.130 & 1.232 & 1.533 & 1.855 & 5.035 & 0.493 & 1.299 & 1.413 & 1.742 & 1.997 & 5.464 \\
\hline 13 & 0.347 & 0.698 & 0.843 & 0.923 & 1.587 & 2.312 & 0.583 & 0.919 & 1.068 & 1.219 & 1.848 & 3.432 & 0.425 & 0.726 & 0.864 & 1.019 & 1.527 & 3.026 \\
\hline 14 & 0.396 & 0.599 & 0.720 & 0.796 & 1.371 & & & 0.660 & 0.770 & 0.893 & 1.370 & & & 0.975 & 1.137 & 1.295 & 1.885 & 3.429 \\
\hline 15 & 0.297 & 0.603 & 0.683 & 0.771 & 1.111 & 1.852 & 0.309 & 0.767 & 0.824 & 0.981 & 1.252 & 2.719 & 0.315 & 0.835 & 0.896 & 1.094 & 1.298 & 3.248 \\
\hline 16 & 0.305 & 0.574 & 0.660 & 0.738 & 1.103 & 1.676 & 0.321 & 0.721 & 0.799 & 0.925 & 1.211 & 2.398 & 0.324 & 0.724 & 0.803 & 0.957 & 1.213 & 2.533 \\
\hline 17 & 0.385 & 0.841 & 0.953 & 1.098 & 1.490 & 3.119 & 0.390 & 1.083 & 1.187 & 1.430 & 1.696 & 4.878 & 0.413 & 1.236 & 1.228 & 1.683 & 1.887 & 6.333 \\
\hline 18 & 0.386 & 0.834 & 0.941 & 1.085 & 1.470 & 3.054 & 0.388 & 1.063 & 1.165 & 1.401 & 1.670 & 4.723 & 0.414 & 1.253 & 1.238 & 1.699 & 1.880 & 6.430 \\
\hline 19 & 0.387 & 0.858 & 0.971 & 1.122 & 1.520 & 3.236 & 0.391 & 1.096 & 1.197 & 1.443 & 1.710 & 4.946 & 0.416 & 1.233 & 1.344 & 1.664 & 1.851 & 6.209 \\
\hline 20 & 0.395 & 0.871 & 0.983 & 1.135 & 1.536 & 3.256 & 0.395 & 1.125 & 1.229 & 1.485 & 1.752 & 5.147 & 0.413 & 1.184 & 1.287 & 1.588 & 1.785 & 5.777 \\
\hline
\end{tabular}

Table 4. Equation coefficients in terms of coded factors ${ }^{\mathrm{a}}$

\begin{tabular}{ccccccccccccc}
\hline & & $\mathrm{b}_{0}$ & $\mathrm{~b}_{1}$ & $\mathrm{~b}_{2}$ & $\mathrm{~b}_{3}$ & $\mathrm{~b}_{4}$ & $\mathrm{~b}_{12}$ & $\mathrm{~b}_{13}$ & $\mathrm{~b}_{14}$ & $\mathrm{~b}_{23}$ & $\mathrm{~b}_{24}$ & $\mathrm{~b}_{34}$ \\
\hline \multirow{6}{*}{$\mathrm{C}_{4}$} & $\mathrm{k}_{1}$ & +0.43 & -0.007 & -0.32 & -0.038 & +0.43 & +0.009 & +0.17 & -0.034 & +0.009 & -0.002 & -0.030 \\
& $\mathrm{k}_{2}$ & +0.92 & -0.041 & -0.021 & -0.20 & +0.92 & +0.019 & +0.006 & -0.016 & +0.022 & -0.018 & -0.014 \\
& $\mathrm{k}_{3}$ & +1.06 & -0.043 & -0.053 & -0.23 & +1.06 & +0.020 & +0.009 & -0.023 & +0.027 & -0.017 & -0.012 \\
& $\mathrm{k}_{\mathrm{P}}$ & +1.21 & -0.060 & -0.063 & -0.29 & +1.21 & +0.024 & +0.017 & -0.019 & +0.031 & -0.009 & -0.012 \\
& $\mathrm{k}_{4}$ & +1.66 & -0.057 & -0.18 & -0.32 & +1.66 & +0.021 & +0.015 & -0.046 & +0.049 & -0.046 & -0.059 \\
& $\mathrm{k}_{5}$ & +3.53 & -0.32 & -0.44 & -1.27 & +3.53 & +0.14 & +0.14 & +0.040 & +0.27 & +0.047 & +0.085 \\
\hline & $\mathrm{k}_{1}$ & +0.45 & -0.009 & -0.063 & -0.017 & -0.007 & +0.013 & -0.0001 & -0.048 & +0.0001 & -0.011 & -0.027 \\
& $\mathrm{k}_{2}$ & +1.09 & -0.073 & +0.001 & -0.19 & -0.14 & +0.050 & +0.003 & -0.043 & -0.010 & +0.021 & +0.002 \\
& $\mathrm{k}_{3}$ & +1.21 & -0.079 & -0.035 & -0.21 & -0.14 & +0.056 & +0.008 & -0.053 & -0.008 & +0.025 & +0.004 \\
$\mathrm{C}_{8}$ & $\mathrm{k}_{\mathrm{P}}$ & +1.46 & -0.091 & -0.053 & -0.30 & -0.15 & +0.054 & -0.003 & -0.036 & +0.003 & +0.023 & -0.013 \\
& $\mathrm{k}_{4}$ & +1.80 & -0.088 & -0.17 & -0.31 & +0.003 & +0.056 & -0.004 & -0.079 & +0.019 & -0.017 & -0.069 \\
& $\mathrm{k}_{5}$ & +4.71 & -0.69 & -0.39 & -1.40 & -0.79 & +0.46 & +0.22 & -0.11 & +0.12 & +0.35 & +0.26 \\
\hline & $\mathrm{k}_{1}$ & +0.50 & +0.021 & -0.052 & -0.045 & -0.002 & -0.015 & +0.008 & +0.012 & -0.004 & -0.043 & -0.022 \\
& $\mathrm{k}_{2}$ & +1.21 & -0.046 & +0.015 & -0.27 & -0.12 & -0.019 & +0.033 & +0.032 & +0.013 & -0.043 & -0.013 \\
& $\mathrm{k}_{3}$ & +1.32 & -0.039 & -0.035 & -0.03 & -0.085 & +0.016 & +0.066 & +0.029 & -0.013 & -0.043 & -0.011 \\
$\mathrm{C}_{18}$ & $\mathrm{k}_{\mathrm{P}}$ & +1.64 & -0.076 & -0.038 & -0.39 & -0.14 & -0.016 & +0.05 & +0.038 & +0.029 & -0.042 & -0.023 \\
& $\mathrm{k}_{4}$ & +1.92 & -0.053 & -0.18 & -0.40 & +0.03 & -0.039 & +0.044 & +0.024 & +0.026 & -0.082 & -0.065 \\
& $\mathrm{k}_{5}$ & +5.71 & -0.64 & -0.64 & -2.07 & -0.62 & +0.11 & +0.36 & +0.18 & +0.55 & -0.01 & +0.036 \\
\hline
\end{tabular}

${ }^{a}$ see Table 3 and equation 1.

strong ability to change the polarity of the mobile phase and the properties of the droplet/bulk interfacial film, it affects the majority of the responses, i.e., the increase of its concentration has a negative effect on $\mathrm{k}$ values which means that all peaks are eluting faster.

The effect of the surfactant (factor $\mathrm{x}_{2}, \mathrm{SDS} / \mathrm{Brij}^{\circledR 35}$ ) is evident for the responses $k_{1}$ and $k_{4}$. The impurity 1 is the most hydrophilic compound which is eluting first, so the increase of the proportion of nonionic surfactant leads to its later elution. Also, higher concentrations of nonionic surfactant affected distancing between pramipexole and impurity 4 . Obviously, the presence of ionic and non-ionic surfactant changed the interfacial properties of microemulsion droplets and caused better separation of this critical pair. 
Table 5. Factors and their interactions with the significant influence on the responses

\begin{tabular}{|c|c|c|c|c|c|c|}
\hline \multirow{2}{*}{ Column } & \multicolumn{6}{|c|}{ Response } \\
\hline & $\mathrm{k}_{1}$ & $\mathrm{k}_{2}$ & $\mathrm{k}_{3}$ & $\mathrm{k}_{\mathrm{P}}$ & $\mathrm{k}_{4}$ & $\mathrm{k}_{5}$ \\
\hline $\mathrm{C}_{4}$ & - & $\mathrm{x}_{3}, \mathrm{x}_{4}$ & $\mathrm{x}_{3}, \mathrm{x}_{4}$ & $\mathrm{x}_{3}, \mathrm{x}_{4}$ & $\mathrm{x}_{2}, \mathrm{x}_{3}$ & $\mathrm{x}_{1}, \mathrm{x}_{2}, \mathrm{x}_{3}, \mathrm{x}_{4}, \mathrm{x}_{23}$ \\
\hline $\mathrm{C}_{8}$ & $\mathrm{x}_{2}, \mathrm{x}_{14}$ & $\mathrm{x}_{1}, \mathrm{x}_{3}, \mathrm{x}_{4}$ & $\mathrm{x}_{1}, \mathrm{x}_{3}, \mathrm{x}_{4}$ & $\mathrm{x}_{1}, \mathrm{x}_{3}, \mathrm{x}_{4}$ & $\mathrm{x}_{1}, \mathrm{x}_{2}, \mathrm{x}_{3}, \mathrm{x}_{14}, \mathrm{x}_{34}$ & $\mathrm{x}_{1}, \mathrm{x}_{3}, \mathrm{x}_{4}$ \\
\hline $\mathrm{C}_{18}$ & $\mathrm{x}_{2}, \mathrm{x}_{3}, \mathrm{x}_{24}$ & $\mathrm{x}_{1}, \mathrm{x}_{3}, \mathrm{x}_{4}$ & $\mathrm{x}_{3}, \mathrm{x}_{4}, \mathrm{x}_{13}$ & $\mathrm{x}_{1}, \mathrm{x}_{3}, \mathrm{x}_{4}$ & $\mathrm{x}_{2}, \mathrm{x}_{3}, \mathrm{x}_{24}, \mathrm{x}_{34}$ & $\mathrm{x}_{1}, \mathrm{x}_{2}, \mathrm{x}_{3}, \mathrm{x}_{4}, \mathrm{x}_{13}, \mathrm{x}_{23}$ \\
\hline
\end{tabular}

$\mathrm{x}_{1}$ : butyl acetate; $\mathrm{x}_{2}: \mathrm{SDS} / \mathrm{Brij}{ }^{\circledR} 35 ; \mathrm{x}_{3}: n$-butanol; $\mathrm{x}_{4}:$ TEA; $\mathrm{x}_{12}-\mathrm{x}_{34}$ : factors interactions.

The significance of TEA (factor $\mathrm{x}_{4}$ ) is reflected by its impact on the responses with the close numerical values: $\mathrm{k}_{2}, \mathrm{k}_{3}$ and $\mathrm{k}_{\mathrm{p}}$. Since these substances possess a basic nature, as always in such case, TEA enabled a fine tuning in the separation of closely eluting peaks. The peak shapes were improved with the slight but sufficient change of bands elution. However, factor $\mathrm{x}_{4}$ had the most pronounced effect on the response $\mathrm{k}_{5}$, because the impurity $\mathbf{5}$, besides being basic, also represents the most hydrophobic analyte in the mixture and the ability of TEA to block silanol groups in this case is the most favorable.

When analyzing the influence of the hydrophobic organic solvent representing the internal organic phase such as butyl acetate (factor $\mathrm{x}_{1}$ ), one must consider the fact that, in some part, it may be distributed to the hydrophobic stationary phase on the surface of the column packing material resulting in an increase in the amount of stationary phase. ${ }^{1}$ This is the most evident when the results from $\mathrm{C}_{8}$ column are observed. On the other hand, the internal oil phase does not affect the responses obtained from the experiments performed on $\mathrm{C}_{4}$ column which could be explained with the lowest hydrophobicity of this column and consequently, with the lack of interactions among microemulsion oil droplets and column surface. However, retention factors of the analyzed substances when resolved on $\mathrm{C}_{18}$ column are not affected by the internal phase in the same extent like on $\mathrm{C}_{8}$ column, probably due to long carbon tails of $\mathrm{C}_{18}$ alkyl chain and subsequent steric hindrance caused by their size.

From this part of the investigation it could be concluded that different factors affect different responses when the results obtained from one column are observed. Moreover, different mobile phase factors affect the responses of the one same substance when it is resolved on three columns due to different interactions between the mobile phases and columns of different lipophilicity. The chromatographic behavior of the impurity $\mathbf{1}$ could be easily explained as it is the most hydrophilic compound which is always eluting first. Stationary phase lipophilicity does not affect this compound at all, and in this case, the only partition system that exists is within the mobile phase: microemulsion droplets/bulk of the eluent. The only factor with a substantial impact on its retention is the content of non-ionic surfactant, and evidently, its partition is governed by the change of droplet surface nature. However, the chromatographic behavior of the impurity $\mathbf{5}$ proved to be the most complex due to its susceptibility to the influences of both mobile and stationary phase. In order to evaluate and interpret its partition behavior properly, the impact of the stationary phase must be further analyzed to make the final conclusion. In addition, the influence of the column lipophilicity on the separation of critical pair pramipexole/ impurity $\mathbf{4}$ should also be taken into account.

Stationary phase influence on the partition behavior of the impurity $\mathbf{5}$ and selected critical pair

Data used for these reviews were obtained from the central point experiments, i.e., four replications with the same mobile phase composition performed on all three columns. The appropriate chromatograms are presented in Figure 2.

The relationships between the chromatographic parameters that describe the partition behavior of the impurity 5 and critical pair pramipexole/impurity $\mathbf{4}$ on different stationary phases are presented in Table 6. Values shown in the Table represent the average values from four experiments.

When observing the impurity $\mathbf{5}$, as expected, the retention factor $k_{5}$ is increasing with the increase of the column lipophilicity, due to affinity of the hydrophobic compound to bind stronger to the columns modified with the longer alkyl chain. Considering the number of theoretical plates $\mathrm{N}$ as a useful measure of column efficiency, the same set of experiments was conducted on three columns with the same properties in terms of their length, diameter and particle size, shape and porosity, but with silica modifiers of different lipophilicity. Since it is supposed that the quantity $\mathrm{N}$ remains approximately constant for different bands in a chromatogram, for a given set of operating conditions (a particular column and mobile phase, with mobile-phase velocity and temperature fixed), ${ }^{19}$ equations $\mathrm{N}=16\left(\mathrm{t}_{\mathrm{R}} / \mathrm{W}\right)^{2}$ and $\mathrm{N}=5.54\left(\mathrm{t}_{\mathrm{R}} / \mathrm{W}_{\mathrm{h}}\right)^{2}$, (W - peak width at the chromatogram base line, $\mathrm{w}_{\mathrm{h}}$ - width 
a)
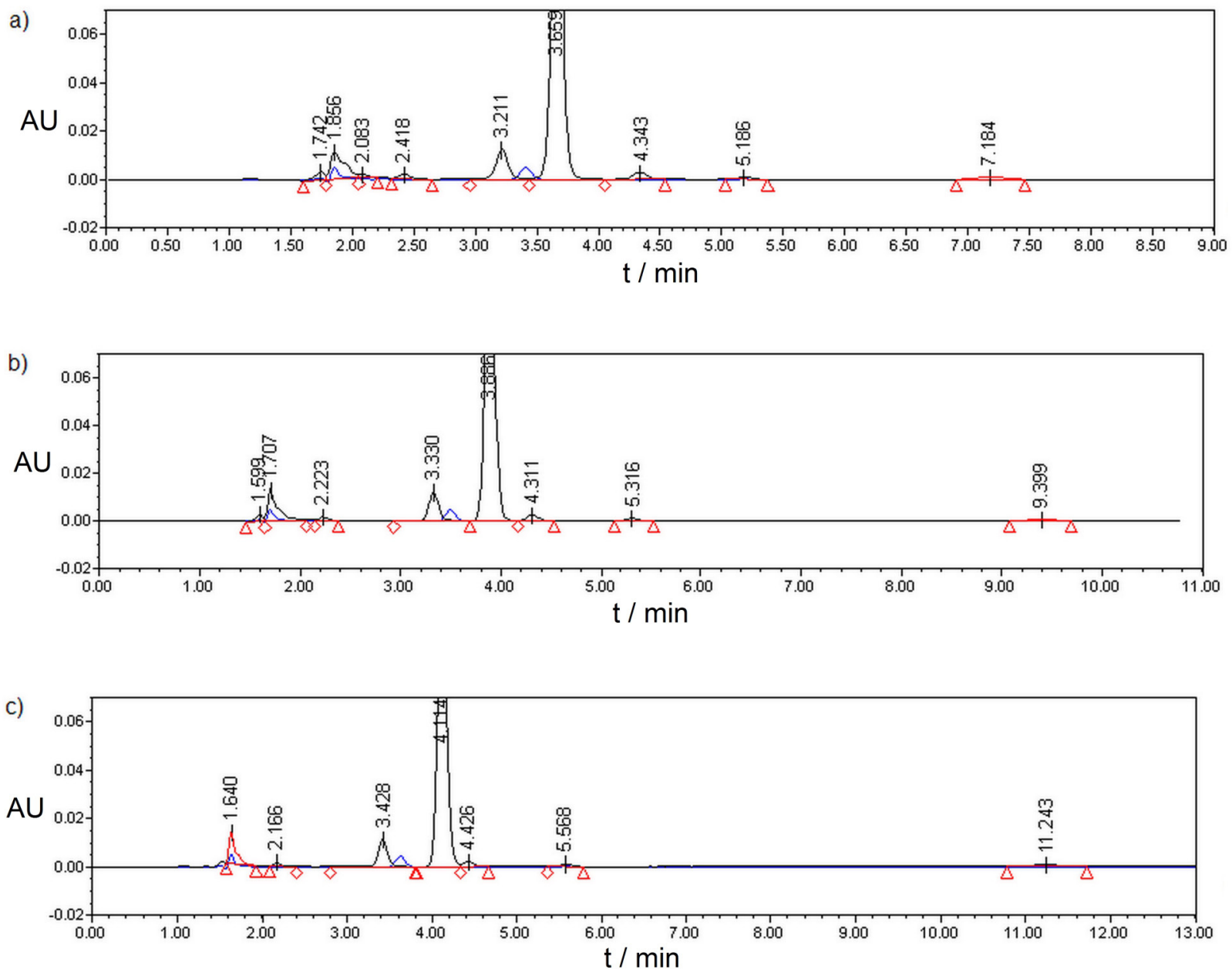

Figure 2. Central point chromatograms performed on (a) C4 column: impurity $\mathbf{1}$ (2.418 min), impurity $\mathbf{2}$ (3.211 min), impurity $\mathbf{3}$ (3.405 min), pramipexole (3.659 min), impurity 4 (4.343 min), unknown impurity (5.186 min), impurity $\mathbf{5}$ (7.184 min); (b) C8 column: impurity $\mathbf{1}$ (2.223 min), impurity $\mathbf{2}$ (3.330 min), impurity 3 (3.497 $\mathrm{min})$, pramipexole (3.886 min), impurity 4 (4.311 min), unknown impurity (5.316 min), impurity $\mathbf{5}$ (9.399 min); (c) C18 column: impurity $\mathbf{1}$ (2.166 $\mathrm{min})$, impurity $\mathbf{2}$ (3.428 $\mathrm{min})$, impurity $\mathbf{3}$ (3.623 $\mathrm{min})$, pramipexole (4.114 $\mathrm{min})$, impurity 4 (4.426 min), unknown impurity (5.568 min), impurity 5 (11.243 $\mathrm{min})$.

Table 6. The influence of the column lipophilicity on the chromatographic parameters of the impurity 5 and critical pair pramipexole/impurity $\mathbf{4}$

\begin{tabular}{lccc}
\hline $\begin{array}{l}\text { Chromatographic } \\
\text { parameters }\end{array}$ & \multicolumn{3}{c}{ Column } \\
\cline { 2 - 4 } & $\mathrm{C}_{4}$ & $\mathrm{C}_{8}$ & $\mathrm{C}_{18}$ \\
\hline $\mathrm{k}_{5}$ & 3.166 & 4.923 & 6.187 \\
$\mathrm{~N}_{5}$ & 4907.1 & 6103.1 & 5723.9 \\
$\mathrm{k}_{\mathrm{P}}$ & 1.110 & 1.439 & 1.658 \\
$\mathrm{k}_{4}$ & 1.504 & 1.707 & 1.851 \\
$\Delta \mathrm{k}$ & 0.394 & 0.268 & 0.193 \\
$\mathrm{R}_{\mathrm{P} / 4}$ & 3.701 & 2.235 & 1.141 \\
\hline
\end{tabular}

$\mathrm{k}_{5}$ - retention factor of the impurity $\mathbf{5} ; \mathrm{N}_{5}$ - number of theoretical plates of the impurity $\mathbf{5} ; \mathrm{k}_{\mathrm{p}}, \mathrm{k}_{4}$ - retention factors of pramipexole and impurity $\mathbf{4}$; $\Delta \mathrm{k}=\mathrm{k}_{4}-\mathrm{k}_{\mathrm{p}} ; \mathrm{R}_{\mathrm{P} / 4}-$ resolution of the critical pair pramipexole/impurity 4 .

of the band at half-height) predict that band width, i.e., band width at half-height will increase proportionately with the retention time. In this case, the increase of peak width $\left(\right.$ or $\left.\mathrm{w}_{\mathrm{h}}\right)$ is not proportional with the increase of retention time, which affects the number of theoretical plates of the analyzed columns. As expected, the value $\mathrm{N}_{\mathrm{C} 4}$ (the number of theoretical plates obtained from $\mathrm{C}_{4}$ column) is the lowest because both $t_{R}$ and $w_{h}$ possess the lowest values when the substance is resolved on this column. The increase in $\mathrm{N}$ caused by the increase of the retention time is evident both on $\mathrm{C}_{8}$ and $\mathrm{C}_{18}$ columns, but with the increase of column lipophilicity, band widening occurs and the significance of width term exceeds the influence of the retention time. Finally, $\mathrm{C}_{8}$ column appears to provide the optimal partition behavior of the observed impurity, both in terms of its efficiency and analyte retention time.

The investigation of the critical pair partition behavior demonstrated the obvious influence of column lipophilicity on the resolution between pramipexole and impurity 4 . The resolution $\left(\mathrm{R}_{\mathrm{s}}\right)$ between peaks of two components may be calculated from the expression: ${ }^{20}$ 
$\mathrm{R}_{\mathrm{s}}=\frac{1.18\left(\mathrm{t}_{\mathrm{R} 2}-\mathrm{t}_{\mathrm{R} 1}\right)}{\mathrm{w}_{\mathrm{h} 1}+\mathrm{w}_{\mathrm{h} 2}}$

where $t_{R 1}$ and $t_{R 2}$ are the retention times of the critical pair of substances and $\mathrm{w}_{\mathrm{h} 1}$ and $\mathrm{w}_{\mathrm{h} 2}$ widths of the band at halfheight. In order to establish the relation between retention factors and resolution, if $t_{R}=t_{0}(k+1)$ (from equation 2), the resolution expression can be transformed as follows:

$\mathrm{R}_{\mathrm{s}}=\frac{1.18 \mathrm{t}_{0}\left(\mathrm{k}_{2}-\mathrm{k}_{1}\right)}{\mathrm{w}_{\mathrm{h} 1}+\mathrm{w}_{\mathrm{h} 2}}$

Even though the retention factors of both substances are increasing with the increase of column lipophilicity, the product of their subtraction is decreasing, and thus, the resolution values (Table 6). As it could be noted, the retention factor of pramipexole is varying in a wider range, because the pramipexole is more sensitive to the decrease of column lipophilicity which leads to its earlier elution. The change of the column also affects the retention of impurity $\mathbf{4}$, but in a smaller extent. The relation of the retention change of both compounds with their resolution is presented in Figure 3.

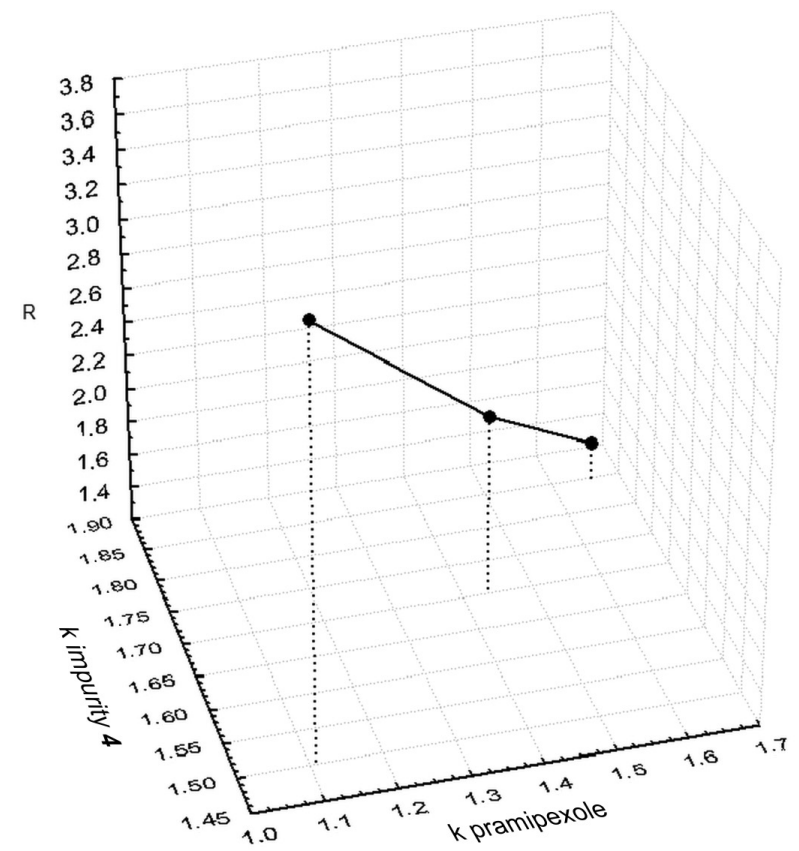

Figure 3. The relation between the critical pair resolution $(\mathrm{R})$ and retention factors $(\mathrm{k})$ of both pramipexole and impurity 4.

The impact of the column efficiency on the resolution expressed as $\mathrm{N}$, indicated an improved peak separation with the decrease of column lipophilicity (Figure 4). The quantity $\mathrm{N}$ for both substances appeared to be stable for the separations carried out on $\mathrm{C}_{4}$ and $\mathrm{C}_{8}$ columns, while a sudden drop in value of $\mathrm{N}_{\mathrm{C} 18}$, especially for the impurity 4 , reflects less ability of $\mathrm{C}_{18}$ column to resolve these adjacent peaks.

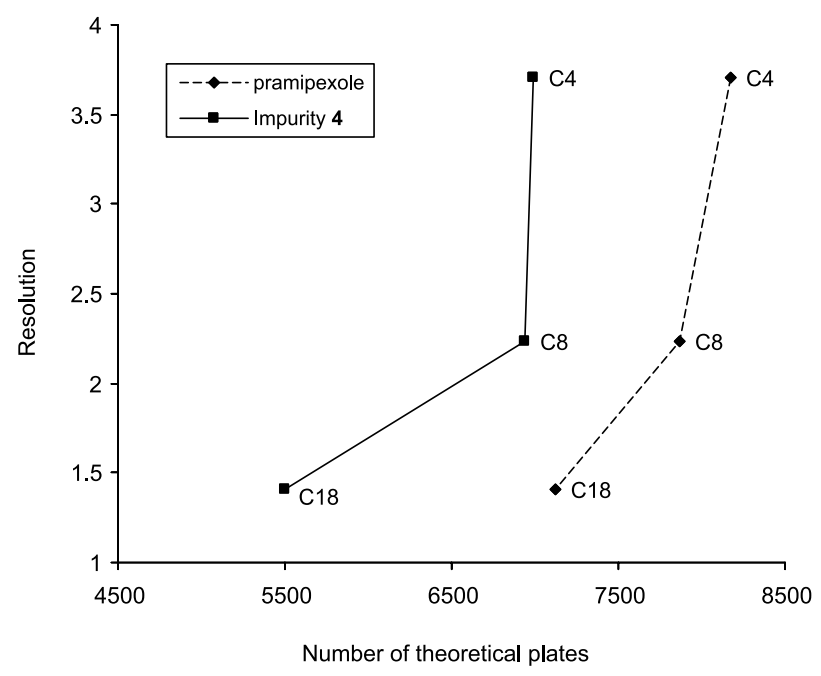

Figure 4. The number of theoretical plates of pramipexole and impurity 4 for the peak pair resolution: the effect of column efficiency on the resolution of the critical pair.

Finally, in MELC systems, it could be noted that the chromatographic behavior of the most lipophilic compound in the mixture (impurity $\mathbf{5}$ ) is the most complex to explain, i.e., both mobile phase composition and stationary phase nature affect its retention. In that context, it is not possible to generally conclude which of the three potential partition systems will be the most influential since it depends on many factors. In this particular case, the system microemulsion droplets/stationary phase was probably the most dominant. However, almost equal effect of the microemulsion droplets/stationary phase partition system and bulk of the eluent/stationary phase partition system was noticed when the separation of the critical pair was considered. Namely, the change of column lipophilicity significantly affected pramipexole's behavior; furthermore, the separation of the critical pair was influenced by the presence of TEA in the eluent bulk and its interaction with the stationary phase, and eventually, the change of droplet nature caused by the presence of non-ionic surfactant imposed a better separation of pramipexole and impurity 4 .

\section{Conclusions}

In microemulsion liquid chromatography analytes retentions are affected by many factors due to the presence of three simultaneous partition systems: first system comprises microemulsion droplets/bulk of the eluent; second, microemulsion droplets/stationary phase and third, bulk of the eluent/stationary phase. This study was devoted to the systematical investigation of the influence of mobile 
phase composition and stationary phase lipophilicity on the partition behavior of the pharmaceutically active substance pramipexole and its five impurities in order to explain the factors that govern this process. It could be seen that the stationary phase lipophilicity does not affect the impurity $\mathbf{1}$ at all, while the only partition system that impacts its chromatography was microemulsion droplets/bulk of the eluent. The retention of the impurity 5 was influenced both by the mobile phase composition and stationary phase nature, so in this case the system microemulsion droplets/ stationary phase proved to be the most significant. For the separation of the critical pair, almost equal effect of the microemulsion droplets/stationary phase partition system and bulk of the eluent/stationary phase partition system was noted. Finally, the comprehension of these processes offers an understanding of advantages that MELC brings. Being a powerful tool for solving different separation challenges and easy to carry out, this method offers a number of possibilities for the application in pharmaceutical industry and routine quality control analysis.

\section{Acknowledgments}

The authors thank to the Ministry of Education and Science of the Republic of Serbia for supporting these investigation through the Project 172052.

\section{References}

1. El-Sherbiny, D. T. M.; El-Ashry, S. M.; Mustafa, M. A.; ElEmam, A. A. -E. -R.; Honoré Hansen, S.; J. Sep. Sci. 2003, 26, 503.

2. Watarai, H.; J. Chromatogr., A 1997, 780, 93.

3. Lawrence, J. M.; Curr. Opin. Colloid Interface Sci. 1996, 1, 826.

4. Marsh, A.; Clark, B.; Altria, K.; Chromatographia 2004, 59, 531.

5. Marsh, A.; Clark, B. J.;. Altria, K. D; J. Sep. Sci. 2005, 28, 2023.
6. El-Sherbiny, D. T.; El-Enany, N.; Belal, F. F.; Hansen, S. H.; J. Pharm. Biomed. Anal. 2007, 43, 1236.

7. McEvoy, E.; Donegan, S.; Power, J.; Altria, K.; J. Pharm. Biomed. Anal. 2007, 44, 137.

8. Li, N.; Hou, X.; Yang, W.; Huang, G.; Ye, X.; Chin. J. Chromatogr. 2009, 27, 323.

9. Momenbeik, F.; Roosta, M.; Nikoukar, A. A.; J. Chromatogr., A 2010, 1217, 3770.

10. Althanyan, M. S.; Assi, K. H.; Clark, B. J.; Nanaee J.; J. Pharm. Biomed. Anal. 2011, 55, 397.

11. Liu, J.; Sun, J.; Sui, X.; Wang, Y.; Hou, Y.; He, Z.; J. Chromatogr., A 2008, 1198-1199, 164.

12. Malenović, A.; Jančić-Stojanović, B.; Vemić, A.; Ivanović, D.; Medenica, M.; J. AOAC Int. 2010, 93, 1102.

13. Jančić, B.; Ivanović, D.; Medenica, M.; Malenović, A.; Chromatographia 2007, 65, 633.

14. Jančić, B.; Ivanović, D.; Medenica, M.; Malenović, A.; Acta Chim. Slov. 2007, 54, 49.

15. Pathare, D. B.; Jadhav, A. S.; Shingare, M. S.; J. Pharm. Biomed. Anal. 2006, 41, 1152.

16. Lau, Y. Y.; Selenka, J. M.; Hanson, G. D;. Talaat, R.; Ichhpurani, N.; J. Chromatogr., B: Anal. Technol. Biomed. Life Sci. 1996, 683, 209.

17. Lau, Y. Y.; Hanson, G. D.; Ichhpurani, N.; J. Chromatogr., B: Anal. Technol. Biomed. Life Sci.1996, 683, 217.

18. Lundstedt, T.; Seifert, E.; Abramo, L.; Thelin, B.; Nyström, A.; Pettersen, J.; Bergman, R.; Chemom. Intell. Lab. Syst. 1998, 42,3 .

19. Snyder, L. R.; Kirkland, J. J.; Introduction to Modern Liquid Chromatography, $2^{\text {nd }}$ ed.; John Wiley \& Sons, Inc.: New York, 1979.

20. European Pharmacopoeia, $7^{\text {th }}$ ed.; European Directorate for the Quality of Medicines and Health Care, Council of Europe, Strasbourg, France, 2010.

Submitted: October 24, 2011 Published online: December 7, 2012 